\title{
A Retrospective Observational Study of Problems Faced by Children and Adolescents with Cancer: A 5-year Experience from a Pediatric Psycho-Oncology Service in India
}

\author{
Jayita Deodhar $^{1}$ Savita S. Goswami2 ${ }^{20}$ Lekhika N. Sonkusare ${ }^{2}$ \\ ${ }^{1}$ Department of Palliative Medicine, Tata Memorial Hospital, Homi \\ Bhabha National Institute, Parel, Mumbai, Maharashtra, India \\ 2 Psycho-oncology Unit, Tata Memorial Hospital, Dr. E. Borges Road, \\ Parel, Mumbai, Maharashtra, India \\ Address for correspondence Jayita Deodhar, MD, DNB, MRCPsych, \\ Department of Palliative Medicine, Tata Memorial Hospital, Homi \\ Bhabha National Institute, Dr. E. Borges Road, Parel, Mumbai, \\ Maharashtra 400012, India (e-mail: jukd2000@yahoo.co.uk).
}

Ind J Med Paediatr Oncol 2021;42:533-539.

\section{Abstract \\ Keywords \\ - pediatric \\ - psycho-oncology \\ - children and adolescents \\ - cancer \\ - India}

Introduction Psychological concerns are common in children and adolescents with cancer, for which they require referral to specialist services. There is a dearth of pediatric psycho-oncology services in India. There are limited studies on emotional and related distress in children.

Objectives To evaluate the types of problems and associated factors in children and adolescents with cancer referred to the pediatric psycho-oncology service in a tertiary care oncology center in India.

Materials and Methods A retrospective analysis of all referrals to the institution's pediatric psycho-oncology service over 5 years was performed. Patients newly referred to the service, up to 18 years of age, with a cancer diagnosis, on active diseasemodifying treatment or supportive care or following up within 2 years of completion of treatment were included. Patients not on any disease-modifying treatment and receiving the best supportive care only were excluded as needs and problems would differ in this group. Patients whose medical records were incomplete were excluded too. Descriptive measures and tests of association were performed for analysis.

Results Of the 278 children referred to the service in 5 years, $66.5 \%$ were males. The average age was 11 years (standard deviation [SD]: 4.5). Most children had hematolymphoid cancers (58.2\%). All reported problems were mainly emotional/behavioral (59\%), physical health-related (21\%), and academic (14\%). Male children, referred from outpatient clinics and undergoing treatment with palliative intent, had more emotional problems, but these factors were not statistically significant.

Conclusion Children and adolescents with cancer had different problems, most commonly emotional/behavioral and physical health-related. Age, gender, and treatment intent were factors associated with emotional problems. Psychosocial care services for children and adolescents with cancer are necessary for low-resource settings.
DOI https://doi.org/ 10.1055/s-0041-1740069. ISSN 0971-5851.
(C) 2021. Indian Society of Medical and Paediatric Oncology. All rights reserved.

This is an open access article published by Thieme under the terms of the Creative Commons Attribution-NonDerivative-NonCommercial-License, permitting copying and reproduction so long as the original work is given appropriate credit. Contents may not be used for commercial purposes, or adapted, remixed, transformed or built upon. (https://creativecommons.org/ licenses/by-nc-nd/4.0/)

Thieme Medical and Scientific Publishers Pvt. Ltd., A-12, 2nd Floor, Sector 2, Noida-201301 UP, India 


\section{Introduction}

The incidence of childhood cancer in most populations in the world ranges from 75 to 150 per million children per year. ${ }^{1}$ In India, 1.6 to $4.8 \%$ of all cancers are seen in children below 15 years of age, most commonly acute lymphoblastic leukemia. The most common solid tumors are brain tumors, mainly gliomas and medulloblastomas. ${ }^{2}$

Cancer is a traumatic experience for a child who faces numerous stressors and has to adapt to physical and psychosocial challenges, disrupting typical family, social, and school life. ${ }^{3-7}$ They experience illness-related uncertainties, academic, social, self-esteem, and depressive issues. ${ }^{8,9}$ Authors have described mood and sleep disturbances, behavioral, multiple somatic and post-traumatic stress symptoms, and peer interaction difficulties in these patients. ${ }^{10-12}$

Studies have specifically addressed psychosocial issues in adolescent patients. Neville's exploratory, descriptive study found that among the various disease groups, adolescents with leukemia experienced the most significant psychological distress. ${ }^{13}$ Abrams et al have emphasized the impact of cancer on adolescents' physical and emotional health. ${ }^{14}$ Zebrack et al have noted clinically significant chronic distress in $12 \%$ of adolescents and young adults with cancer through the first year following diagnosis. ${ }^{15}$

Most of the studies mentioned above were done in western nations. A few studies done in South East Asia have documented anxiety and depressive symptoms and somatic, social and behavioral problems. ${ }^{16-18}$

In India, very few studies have looked at psychosocial problems in children with cancer. Banerjee et al described excellent psychosocial functioning in patients and survivors in a study on music therapy. ${ }^{19}$ In contrast, other authors found that almost $61 \%$ of children with acute lymphoblastic leukemia during the first remission experienced emotional distress. ${ }^{20,21}$ Thus, the available literature from India is limited to children having a specific cancer diagnosis or survivors. Also, the distress rates reported are variable. In particular, no study, to our knowledge, has specifically addressed problems faced by children and adolescents with cancer, nor were they assessed in a specialist psychooncology service setting.

We conducted a specialist pediatric psycho-oncology service in a tertiary cancer care center in India, provided by a multidisciplinary mental health professional team and based on a consultation-liaison model. For this study, we aimed to identify the types of problems and factors associated with children and adolescents' emotional/behavioral problems with cancer referred to our specialist pediatric psycho-oncology service.

\section{Materials and Methods}

We conducted a retrospective observational study in the psycho-oncology clinic of a metropolitan tertiary cancer care center. We retrospectively analyzed patient-related data from medical charts, psycho-oncology assessment sheets, and electronic medical records of all new referrals of children and adolescents with cancer to the psychooncology service for five years from January 2011 to December 2015. We included records of patients of age up to 18 years, with a cancer diagnosis and active disease-modifying treatment or supportive care for the management of cancer treatment-related adverse effects or on follow-up after completion of treatment for 2 years or less, using purposive sampling. Patients referred for neurocognitive assessment as part of research trials, on follow-up for more than 2 years since treatment completion, and records with incomplete data were excluded. Patients not on any disease-modifying treatment referred to palliative care services and receiving the best supportive care only were also excluded.

As part of our standard care in psycho-oncology assessment and management of the patients, we take a clinical history and interview the patient for mental status examination. This assessment includes sociodemographic information, disease- and treatment-related data, birth and developmental history, personal history, types of problems reported in any domain (physical, emotional, academic, family/peer relationship, and other), past history of emotional/behavioral problems, family history of mental health issues, and details of the mental status examination. The emotional/behavioral problems were noted in the history and interview and documented in the case records (Supplementary File S1).

The primary outcome was to identify the number and types of problems reported by children and adolescents with cancer referred to our pediatric psycho-oncology service. Our secondary outcome was to examine the factors associated with a) any reported problem in any domain (physical, emotional, academic, family/peer/interpersonal, other) and b) emotional problems specifically.

Data obtained were 1) sociodemographic (age, gender, financial ability, and family structure), 2) outpatient or inpatient status, 3) site-specific cancer diagnosis, 4) treatment status (active disease-directed treatment/supportive care(follow-up), 5) past history of emotional problems, 6) problems expressed in the clinical interview (number and type), and 7) the presence of family conflict (as expressed by patients in the clinical interview and documented in the records). The parents' ability to pay hospital medical charges was noted depending on the family's income and the type of registration (general or private category), as recorded in the patient hospital registration details. The problems were categorized into physical, emotional (worry, anxiety, sadness, irritability, depression, feelings of guilt, less hopeful, or low self-esteem), cognitive/academic (difficulties in achieving expected grades in education), family relationship (issues pertaining to family dynamics or communication as reported by patients or parents or family conflict), or interpersonal or peer relationship, as recorded from the history, clinical interview, and mental status examination in the departmental standard psycho-oncology assessment sheets. If there were multiple problems, we recorded the problem that the patients expressed as the most distressing in the assessment notes (Supplementary File S2). 
Outcome measures were demographic and clinical variables, the presence of problems in children and adolescents, and disease- and treatment-related and other factors associated with problems in general and emotional problems.

\section{Statistical Analysis}

We used descriptive statistics for demographic, clinical variables, numbers and types of problems. Equivalency of proportions in contingency tables was tested using the chisquared test or Fisher's exact test, as applicable for examining the association of factors with the presence of problems (any type) and emotional problems. Statistical analyses were performed using SPSS 20 (IBM SPSS Statistics for Windows, Version 20.0. Armonk, NY: IBM Corp.). We excluded the missing data from analysis and a p-value of 0.05 or less was considered significant.

\section{Ethics}

The procedures followed were in accordance with the ethical standards of the responsible committee on human experimentation and with the Helsinki Declaration of 1964, as revised in 2013. The Institutional Ethics Committee of Tata Memorial Hospital, Mumbai, approved the study (Ref. no. 1674 dated May 11, 2016). A waiver of informed patient consent was obtained due to the retrospective nature of the study.

\section{Results}

\section{Patient Characteristics}

The total number of patients referred to the specialist pediatric psycho-oncology service in the 5 years and included in the study was 278 . Out of 278 patients, 185 (66.5\%) of the referrals were males, and 193 (70\%) were outpatients. The mean ages were 11.01 years (standard deviation [SD]: 4.54) for the overall sample, 7.45 years (SD: 3.03) for under 12 years, and 15 years (SD: 1.6$)$ for adolescents. In addition, 167 (60\%) patients belonged to a nuclear family and 267 (96\%) families had no or limited ability to afford medical payments. However, 261 (94\%) families did not express any financial constraints. Family conflicts were reported in 9// 278 (3\%) of the patients (-Table 1).

Leukemias and lymphomas were the most common cancers in the referred children and adolescents, seen in 162/278 (58.2\%) patients. The most common solid tumors were of the brain and bone and soft tissue $(45,16.2 \%$ and $44,15.8 \%$ patients, respectively). Hematolymphoid cancers were seen more in children than in adolescents (54.3\% vs. $45.7 \%$ ). Among solid tumors, neuroblastomas, retinoblastomas, and Wilms tumor were seen only in children (5, 3, and 1, respectively). Also, $245 / 278$, i.e., $88 \%$ of the patients were on treatment with curative intent at the referral time (-Table 1).

\section{Problems Reported}

All children and adolescents referred to the psycho-oncology service had expressed problems. For example, 164/278
Table 1 Patients' characteristics

\begin{tabular}{|c|c|c|c|}
\hline Variable & & $n$ & Percentage \\
\hline \multirow[t]{2}{*}{ Gender } & Male & 185 & 66.5 \\
\hline & Female & 93 & 33.5 \\
\hline \multirow[t]{2}{*}{ Age } & $<12$ y & 148 & 53.2 \\
\hline & $>12 y$ & 130 & 46.8 \\
\hline \multirow{2}{*}{$\begin{array}{l}\text { Outpatient/ } \\
\text { inpatient }\end{array}$} & Outpatient & 193 & 69.4 \\
\hline & Inpatient & 85 & 30.6 \\
\hline \multirow{3}{*}{$\begin{array}{l}\text { Able to pay } \\
\text { medical charges }\end{array}$} & No & 106 & 38.1 \\
\hline & Partial & 161 & 57.9 \\
\hline & Yes & 11 & 4.0 \\
\hline \multirow[t]{2}{*}{ Family structure } & Nuclear & 167 & 60.1 \\
\hline & Joint & 111 & 39.9 \\
\hline \multirow[t]{8}{*}{ Cancer diagnosis } & $\begin{array}{l}\text { Lymphomas } \\
\text { and leukemias }\end{array}$ & 162 & 58.2 \\
\hline & $\begin{array}{l}\text { Bone and } \\
\text { soft tissue }\end{array}$ & 44 & 15.8 \\
\hline & Brain & 45 & 16.3 \\
\hline & Neuroblastoma & 5 & 1.8 \\
\hline & Retinoblastoma & 3 & 1.1 \\
\hline & Germ cell tumors & 6 & 2.2 \\
\hline & Wilms tumor & 1 & 0.3 \\
\hline & Others & 12 & 4.3 \\
\hline \multirow[t]{3}{*}{ Treatment } & Curative intent & 245 & 88.1 \\
\hline & Palliative intent & 6 & 2.2 \\
\hline & Supportive care & 27 & 9.7 \\
\hline \multirow[t]{2}{*}{ Family conflicts } & Present & 9 & 3.2 \\
\hline & Absent & 269 & 96.8 \\
\hline \multirow{2}{*}{$\begin{array}{l}\text { Financial } \\
\text { stressors }\end{array}$} & Present & 17 & 6.1 \\
\hline & Absent & 261 & 93.9 \\
\hline
\end{tabular}

patients (59\%) had emotional/behavioral problems. Physical health-related problems were seen in 58 of 278 (21\%) and academic issues in 39/278 patients (14\%). In addition, 17/278 patients $(6.1 \%)$ reported family/peer/interpersonal relationship problems and other issues.

The types of problems seen in the two groups of children and adolescents are described in - Table 2. Emotional problems were seen in 89/148 (60\%) of the children compared with $75 / 130$ (57.7\%) of adolescents, whereas physical healthrelated problems were seen more in 31/130 adolescents (23.8\%) than in children $(27 / 148,18.2 \%)$.

\section{Associated Factors}

Factors associated with emotional/behavioral problems are outlined in - Table 3. More outpatients than inpatients faced emotional problems. Males had a higher prevalence of 
Table 2 Types of problems in children versus adolescents $(N=278)$

\begin{tabular}{|l|l|l|l|l|}
\hline Types of problems & $\begin{array}{l}\text { Children } \\
\boldsymbol{n}(\%)\end{array}$ & $\begin{array}{l}\text { Adolescents } \\
\boldsymbol{n}(\%)\end{array}$ & Odds Ratio (95\% Cl) & $p$-Value \\
\hline Emotional & $89(60.1)$ & $75(57.7)$ & $1.1(0.68$ to 1.78$)$ & 0.68 \\
\hline Physical & $27(18.2)$ & $31(23.8)$ & $1.14(0.39$ to 1.27$)$ & 0.25 \\
\hline Academic & $23(15.5)$ & $16(12.3)$ & $1.31(0.66-2.6)$ & 0.43 \\
\hline Family/peer/interpersonal & $7(4.7)$ & $6(4.6)$ & $1.02(0.33-3.13)$ & 0.96 \\
\hline Other & $2(1.4)$ & $2(1.5)$ & $0.87(0.12-6.31)$ & 0.89 \\
\hline Total & 148 & 130 & & \\
\hline
\end{tabular}

Table 3 Factors associated with the presence of emotional/behavioral problems

\begin{tabular}{|c|c|c|c|c|c|}
\hline Sr. No. & Variables & Number of patients & $\begin{array}{l}\text { Patients with emotional } \\
\text { problems }-n(\%)\end{array}$ & Odds ratio $(95 \% \mathrm{Cl})$ & $p$-Value \\
\hline \multirow[t]{3}{*}{1} & Admission status & \multirow[t]{2}{*}{193} & \multirow[t]{2}{*}{$116(60.1)$} & \multirow[t]{3}{*}{$1.16(0.69-1.94)$} & \multirow[t]{3}{*}{0.57} \\
\hline & Outpatient & & & & \\
\hline & Inpatient & 85 & $48(56.4)$ & & \\
\hline \multirow[t]{3}{*}{2} & Age & & & \multirow[t]{3}{*}{1.1 (0.68 to 1.78$)$} & \multirow[t]{3}{*}{0.68} \\
\hline & 12 y or less & 148 & $89(60.1)$ & & \\
\hline & $>12 y$ & 130 & $75(57.7)$ & & \\
\hline \multirow[t]{3}{*}{3} & Sex & \multirow[t]{2}{*}{185} & \multirow[t]{2}{*}{$111(60)$} & \multirow[t]{3}{*}{$1.13(0.68-1.87)$} & \multirow[t]{3}{*}{0.63} \\
\hline & Male & & & & \\
\hline & Female & 93 & $53(56.9)$ & & \\
\hline \multirow[t]{4}{*}{4} & $\begin{array}{l}\text { Able to pay } \\
\text { medical charges }\end{array}$ & \multirow[t]{2}{*}{106} & \multirow[t]{2}{*}{$61(57.5)$} & \multirow[t]{4}{*}{$0.90(0.55-1.48)$} & \multirow[t]{4}{*}{0.89} \\
\hline & No & & & & \\
\hline & Partial & 161 & $96(59.6)$ & & \\
\hline & Yes & 11 & $7(63.6)$ & & \\
\hline \multirow[t]{3}{*}{5} & Family status & \multirow[t]{2}{*}{167} & \multirow[t]{2}{*}{$99(59.2)$} & \multirow[t]{3}{*}{$1.03(0.63-1.67)$} & \multirow[t]{3}{*}{0.904} \\
\hline & Nuclear & & & & \\
\hline & Joint & 111 & 65 (58.5) & & \\
\hline \multirow[t]{3}{*}{6} & Family conflict & \multirow[t]{2}{*}{269} & \multirow[t]{2}{*}{159 (59.1) } & & \multirow[t]{3}{*}{0.83} \\
\hline & No & & & & \\
\hline & Yes & 9 & $5(55.5)$ & & \\
\hline \multirow[t]{3}{*}{7} & Cancer diagnosis & & & \multirow[t]{3}{*}{$1.48(0.91-2.40)$} & \multirow[t]{3}{*}{0.112} \\
\hline & Hematolymphoid & 162 & 102 (62.9) & & \\
\hline & Solid & 116 & $62(53.4)$ & & \\
\hline \multirow[t]{4}{*}{8} & Treatment & & & \multirow[t]{4}{*}{$1.33(0.62-2.84)$} & \multirow[t]{4}{*}{0.694} \\
\hline & Curative intent & 145 & $85(59.2)$ & & \\
\hline & Palliative intent & 6 & $4(66.6)$ & & \\
\hline & Supportive care & 27 & $13(48.1)$ & & \\
\hline
\end{tabular}

emotional problems as compared with females (111/185, $60 \%$ vs. 53/93, 56.9\%). Emotional/behavioral issues were seen almost equally in patients belonging to nuclear and joint families. The proportion of children and adolescents having emotional problems was slightly higher in families able to pay hospital charges than those who had none or limited ability (7/11, 63\% vs. $157 / 267,59 \%)$. Although there was a trend for the factors mentioned above to emotional/behavioral problems, none of the factors were statistically significant. 


\section{Discussion}

We describe our large-series analysis results covering 5 years on problems expressed by children and adolescents with any cancer diagnosis referred to a pediatric psycho-oncology service in India. Previous studies done in India have focused on survivors of childhood cancer and in children with specific cancers such as acute leukemias. ${ }^{20,21}$

All patients referred to our pediatric psycho-oncology service expressed problems. Emotional/behavioral problems were the most common, expressed by $59 \%$ of the children and adolescents ( $60 \%$ of children and $58 \%$ of adolescents) with cancer. Physical problems were seen in $21 \%$ of patients. This figure is in line with previous studies by Hedström et al in which the authors noted that emotional and physical domains were sources of distress by children and adolescents with cancer. ${ }^{22}$ Enskar and von Essen observed that children receiving cancer treatment experienced more psychosocial than physical stressors, as compared with those who had completed treatment. ${ }^{23}$

We found that emotional/behavioral and academic issues were more common in children, and physical health-related problems were more frequently expressed by adolescents. Other authors have reached a similar conclusion, and they noted that children and adolescents with cancer process their distress differently according to their age. ${ }^{17,18}$ Interestingly, this finding of differences, e.g., children and adolescents' difficulties with cancer, has come from studies done in the South East Asian region. ${ }^{16,17,24}$ Because we also found this difference in our study, we speculated whether there might be some cultural explanations. Li et al have performed a wide survey in Asia regarding the care of adolescents and young adults with cancer. ${ }^{25}$ This inquiry brought out the suboptimal provision of oncological care for this group of patients. However, differences between children and adolescents related to their concerns were not the scope of this study. Zebrack and Isaacson have raised the possibility that adolescents might have been able to cope better, leading to better self-management, thus resulting in less emotional problems. ${ }^{26}$ They are also very conscious of health and hence, maybe more concerned about their physical health-related matters.

Nonetheless, we observed that $58 \%$ of adolescents experienced emotional problems, much higher than 12 to $15 \%$ found by Zebrack et al. ${ }^{15}$ It should be noted that the latter finding was for chronic and delayed distress, and the study included adolescent and young adult groups and not children. This result is different from our study population, i.e., children and adolescents, and we looked at problems of children and adolescents with cancer expressed at referral to our psycho-oncology service.

Only approximately $4.5 \%$ of both children and adolescents expressed any problem with interpersonal relationships, and $3 \%$ reported family conflicts. Erker et al found, in their study of the effect of childhood cancer on family functioning, that children's relationship with family worsened if their siblings were depressed. ${ }^{27}$ Katz et al stated that parent-child conflicts tended to occur during later months of treatment. ${ }^{28} \mathrm{An}$ explanation for our finding could be that these problems were probably not perceived as significant compared with emotional or physical problems. We did not specifically look at how long these conflicts were present or the dyad in which these occurred (patient-parent/sibling). Also, 245 out of 278 (88\%) patients referred to our specialist pediatric psychooncology service were on active disease-directed treatment with curative intent. This figure is consistent with what has been found by other authors who concluded that children and adolescents experienced various problems during the demanding treatment process. ${ }^{4,23}$

Hematolymphoid, brain, and bone cancers were the three most frequent diagnoses in $90 \%$ of the referred patients, a finding similar to other studies. ${ }^{2,29}$ In studying the factors associated with emotional/behavioral problems, we noted that these were present more in patients with hematolymphoid cancers than in those with solid tumors (63\% vs. $53 \%$ ). Allart-Vorelli et al in their systematic review recorded that psychological quality of life $(\mathrm{QoL})$ is affected in hematological cancers. ${ }^{30}$ The intensity and duration of treatment could be contributing to the higher prevalence of emotional problems in the children and adolescents included in our study. Also, our patients travel far from their homes, often from different states of India, to undergo treatment, and they need to stay in temporary accommodation away from their siblings and peers and their familiar environment. This factor may have led to more psychological problems. We also found that a higher proportion of patients undergoing treatment with palliative intent had emotional problems than those undergoing curative or supportive treatment. The disease's burden being higher and probable survival being lower could be explanatory factors for a more significant psychological impact on patients undergoing treatment with palliative intent. We noted a trend for male gender and outpatient status being associated with emotional problems, but these were not statistically significant. A recent retrospective analysis by Sohn et al on variables related to psychological distress experienced by children and adolescents diagnosed with cancer did not find any statistically significant factor. ${ }^{31}$ Our finding corroborates with this report. However, Sohn et $\mathrm{al}^{31}$ mainly focused on maternal depression and not on age, gender, family, disease, treatment, and other parameters that we looked at. Also, the study population was inpatients and within 3 months of the diagnosis, in contrast to the patients referred to our service at any point in their disease trajectory before completion of 2 years of treatment.

It is important to highlight that financial constraints were not a factor associated with the presence of problems. Although $96 \%$ of families in our study were unable or partially able to pay medical charges, they did not report financial stressors. It had been seen earlier that many children used to default on treatment due to finances. To address this problem, the institution and department had taken necessary steps to have their social service program, whereby all patients are given financial help for treatment so that they could continue on their treatment course. Hence, all children and adolescent cancer patients are provided pecuniary help from the hospital and pediatric oncology 
social services unit. ${ }^{32}$ Family structure and conflict were not associated with emotional problems. Maybe, these issues were not expressed, even though present.

These results provide evidence that emotional/behavioral difficulties and physical distress are most common in the referred children and adolescents with cancer in India, in keeping with previous studies in other countries. ${ }^{4}$

There are certain limitations to our study. It was a retrospective analysis done on a referral-based clinical practice. However, the period for the study was 5 years, covering a large number of patients. It helped to identify trends in the referral patterns seen. All patients referred to us had expressed some problem. The referral bias is understandable; because ours is a specialized psycho-oncology service at levels 3 and 4 equivalence as per the National Institute of Clinical Excellence (NICE) guidelines, (National Institute for Clinical Excellence, 2004) Guidance on Cancer Services: Improving Supportive and Palliative Care for Adults with Cancer (Cancer service guideline CSG4), only the patients with significant problems who could not be addressed at levels 1 and 2 would be referred to us. ${ }^{33}$ The institution's pediatric oncology service has counselors and lay volunteers who could address certain problems faced by some of the patients and referred those with complex symptoms to us. Although this practice tied in well with the guidelines, demonstrating correct identification and appropriateness of referrals, it led to a decrease in the number of patients referred to our service ( $\sim 22 \%$ of all patients needing psychosocial support in the specified study period). This restriction could be addressed by integrating psycho-oncology in the pediatric oncology clinic itself. We did not address time since diagnosis at the time of patient referral to our service. Although some authors have addressed dispositional styles as more predictive of distress than diagnosis or treatment, we did not study this factor in our analysis. ${ }^{34,35}$ Academic problems were as reported by child/parent and not according to formal neurocognitive testing. Formal psychiatric diagnoses were not a part of this study, as our aim was to understand the nature of problems in general faced by this patient group. ${ }^{15}$ We did not use any rating scale but conducted clinical interviews for the assessments with an interdisciplinary approach, signifying a more comprehensive evaluation process. Our study was retrospective in design. Further research should focus on prospective studies in understanding the changes in needs and concerns in children and adolescents diagnosed with cancer along their treatment trajectory, as well as on clinical psychiatric disorders.

\section{Conclusion}

This is the first report of 5-year data on children and adolescents with cancer referred to a specialist pediatric psycho-oncology service in India. Our results indicate that children and adolescents with cancer have different emotional and physical health problems, academic performance, and relationship domains. Emotional/behavioral problems were the most common and seen in almost $60 \%$ of the referred patients. Although these problems tended to be more in children than adolescents, males, and those attending outpatient clinics, these differences were not statistically significant. Our study contributes to the existing literature in understanding issues in children and adolescents referred to pediatric psycho-oncology services. It highlights the need for service enhancements in psycho-oncology using structured protocols for assessment and interventions should be formulated and audited for quality-of-care provision. Further research in prospective observational and outcome studies is needed to look at long-term outcomes and the effectiveness of interventions. National cancer care policies should incorporate psychosocial services for children and adolescents with cancer with the availability of appropriate interventions, especially in low-resource settings.

\section{Authors' Contributions}

The first and second authors contributed to the concept and design, conduct, data collection and analysis of the study, and manuscript preparation.

The third author contributed to the concept and design, and data collection of the study.

The paper has been read and approved by all the authors.

\section{Presentation}

This study has been presented as an oral presentation at the International Psycho-Oncology Society's Annual Congress in Hong Kong in 2018.

\section{Funding}

None.

\section{Conflict of Interest}

None declared.

\section{Acknowledgments}

We would like to thank the patients and the staff in the psycho-oncology department.

\section{References}

1 Ferlay J, Soerjomataram I, Ervik M, et al. GLOBOCAN 2012 v1.0, Cancer Incidence and Mortality Worldwide: IARC CancerBase. No. 11 [Internet]. Vol. 11, Lyon, France: International Agency for Research on Cancer; 2013

2 Arora RS, Alston RD, Eden TOB, et al. Cancer at ages 15-29 years: the contrasting incidence in India and England. Pediatr Blood Cancer 2012;58(01):55-60

3 Fochtman D. The concept of suffering in children and adolescents with cancer. J Pediatr Oncol Nurs 2006;23(02):92-102

4 Gerali M, Servitzoglou M, Paikopoulou D, Theodosopoulou H, Madianos M, Vasilatou-Kosmidis H. Psychological problems in children with cancer in the initial period of treatment. Cancer Nurs 2011;34(04):269-276

5 McCaffrey CN. Major stressors and their effects on the well-being of children with cancer. J Pediatr Nurs 2006;21(01):59-66

6 Mitchell W, Clarke S, Sloper P. Care and support needs of children and young people with cancer and their parents. Psychooncology 2006;15(09):805-816

7 Patenaude AF, Kupst MJ. Psychosocial functioning in pediatric cancer. J Pediatr Psychol 2005;30(01):9-27 
8 Wallace ML, Harcourt D, Rumsey N, Foot A. Managing appearance changes resulting from cancer treatment: resilience in adolescent females. Psychooncology 2007;16(11):1019-1027

9 Woodgate R, McClement S. Symptom distress in children with cancer: the need to adopt a meaning-centered approach. J Pediatr Oncol Nurs 1998;15(01):3-12

10 Canning S, Bunton P, Talbot Robinson L. Psychological, demographic, illness and treatment risk factors for emotional distress amongst paediatric oncology patients prior to reaching 5-year survivorship status. Psychooncology 2014;23(11):1283-1291

11 Dejong M, Fombonne E. Depression in paediatric cancer: an overview. Psychooncology 2006;15(07):553-566

12 Wakefield CE, McLoone J, Goodenough B, Lenthen K, Cairns DRCR, Cohn RJ. The psychosocial impact of completing childhood cancer treatment: a systematic review of the literature. J Pediatr Psychol 2010;35(03):262-274

13 Neville K. Psychological distress in adolescents with cancer. J Pediatr Nurs 1996;11(04):243-251

14 Abrams AN, Hazen EP, Penson RT. Psychosocial issues in adolescents with cancer. Cancer Treat Rev 2007;33(07):622-630

15 Zebrack BJ, Corbett V, Embry L, et al. Psychological distress and unsatisfied need for psychosocial support in adolescent and young adult cancer patients during the first year following diagnosis. Psychooncology 2014;23(11):1267-1275

16 Liang HF, Chiang YCYC, Chien LY, Yeh CH. A comparison of emotional/behavioural problems between Taiwanese children with cancer and healthy controls. J Clin Nurs 2008;17(03):304-311

17 Li HC, Chung OKCS, Chiu SY. The impact of cancer on children's physical, emotional, and psychosocial well-being. Cancer Nurs 2010;33(01):47-54

18 Li HC, Chung OK, Ho KY, Chiu SY, Lopez V. Coping strategies used by children hospitalized with cancer: an exploratory study. Psychooncology 2011;20(09):969-976

19 Banerjee P, Mukhopadhyay S, Pal NMA. Music therapy as a tool of psychotherapy in adolescent cancer patients. J Ann Oncol. 2014; 25(04):IV 481. https://doi.org/10.1093/annonc/mdu352.2

20 Ghosh S, Mukhopadhyay S, Gupta P, Chitalkar PGMA. Psychological problems of survival of pediatric cancer patients in their adolescence-an experience from eastern India. Ann Oncol. Supplement 2007(ix193). Doi: 1093/annonc/mdm328

21 Sharan P, Mehta M, Chaudhry VP. Coping and adaptation in acute lymphoblastic leukemia. Indian J Pediatr 1995;62(04):467-471

22 Hedström M, Haglund K, Skolin I, von Essen L. Distressing events for children and adolescents with cancer: child, parent, and nurse perceptions. J Pediatr Oncol Nurs 2003;20(03):120-132
23 Enskär K, von Essen L. Physical problems and psychosocial function in children with cancer. Paediatr Nurs 2008;20(03): $37-41$

24 Cai X, Cram P, Li Y. Origination of medical advance directives among nursing home residents with and without serious mental illness. Psychiatr Serv 2011;62(01):61-66

25 Li CK, Dalvi R, Yonemori K, et al. Care of adolescents and young adults with cancer in Asia: results of an ESMO/SIOPE/SIOP Asia survey. ESMO Open 2019;4(03):e000467

26 Zebrack B, Isaacson S. Psychosocial care of adolescent and young adult patients with cancer and survivors. J Clin Oncol 2012;30 (11):1221-1226

27 Erker C, Yan K, Zhang L, Bingen K, Flynn KE, Panepinto J. Impact of pediatric cancer on family relationships. Cancer Med 2018;7(05): $1680-1688$

28 Katz LF, Fladeboe K, King K, et al. Trajectories of child and caregiver psychological adjustment in families of children with cancer. Health Psychol 2018;37(08):736-745

29 Satyanarayana L, Asthana S, Labani S P. Childhood cancer incidence in India: a review of population-based cancer registries. Indian Pediatr 2014;51(03):218-220

30 Allart-Vorelli P, Porro B, Baguet F, Michel A, Cousson-Gélie F. Haematological cancer and quality of life: a systematic literature review. Blood Cancer J 2015;5(04):e305

31 Sohn IJ, Han JW, Hahn SM, Song DH, Lyu CJ, Cheon KA. Factors associated with emotional distress in children and adolescents during early treatment for cancer. Yonsei Med J 2017;58(04): 816-822

32 Narula G, Prasad M, Jatia S, et al. Clinicoepidemiological profiles, clinical practices, and the impact of holistic care interventions on outcomes of pediatric hematolymphoid malignancies - a 7-year audit of the pediatric hematolymphoid disease management group at Tata Memorial Hospital. Indian J Cancer 2017;54(04): 609-615

33 National Institute for Health and Care Excellence. Improving supportive and palliative care for adults with cancer. 2004 Accessed September 2, 2021at: https://www.nice.org.uk/guidance/csgsp

34 Howard Sharp KM, Rowe AE, Russell K, Long A, Phipps S. Predictors of psychological functioning in children with cancer: disposition and cumulative life stressors. Psychooncology 2015; 24(07):779-786

35 Phipps S, Jurbergs N, Long A. Symptoms of post-traumatic stress in children with cancer: does personality trump health status? Psychooncology 2009;18(09):992-1002 